\title{
Allelopathic effects of Epichlö̈ fungal endophytes: experiment and meta-analysis
}

\author{
Heather A. Hager \\ Wilfrid Laurier University Department of Biology, Waterloo, Ontario, Canada \\ hhager@wlu.ca \\ Maija Gailis \\ Environment and Climate Change Canada, Climate Change Branch, Gatineau, QC Canada \\ maijagailis@live.ca \\ Jonathan A. Newman \\ Wilfrid Laurier University Department of Biology, Waterloo, Ontario, Canada \\ jonathannewman@wlu.ca
}

November 10, 2021

\begin{abstract}
Host-specific Epichloë spp.endophytic fungal symbionts of pooid grasses that produce herbivoredeterring alkaloids and alter the grass host's metabolite and protein profiles. Early observations suggested that Epichloë may have negative allelopathic effects on neighbouring plant species, particularly Trifolium spp. clovers, but subsequent allelopathy tests produced variable results. We examined two hypotheses: (1) Epichloë strains differ in allelopathic effect, and (2) Epichlö̈ allelopathy negatively affects other plant species. We performed a greenhouse experiment using root exudates from Lolium perenne L. hosting different E. festucae var. lolii (Latch, M.J. Chr. \& Samuels) C.W. Bacon \& Schardl strains to compare their allelopathic effects on native legumes and forbs. We then used meta-analysis to examine the evidence to date for allelopathic effects of Epichloë endophytes. We found little difference in effect among E. festucae var. lolii strains and very little evidence for negative allelopathic effects of Epichloë in cool-season grasses across a range of methodologies, target plant species, and response measures. Negative allelopathic effects were detected only for root hair measures, which were from a single study. Positive effects on biomass were found for some experimental subgroups, including legumes. However, the majority of response variables showed no evidence for Epichloë allelopathy. Although there is currently little evidence for negative Epichloë allelopathic effects, our meta-analysis identified several research gaps. Experiments testing the functional belowground effects of Epichloë presence may help to determine its effects on non-host plant performance via plant-soil feedbacks.
\end{abstract}


Keywords: : allelopathy; Neotyphodium; plant-soil feedback; root exudates; soil conditioning; symbiosis

\section{Introduction}

Plants release a variety of resource and non-nutritive compounds into the environment through root exudates, leachates, volatiles, and decomposing tissues. ${ }^{1-3}$ Some of the non-nutritive compounds can have allelopathic effects, which may be positive or negative and are defined as stimulatory or inhibitory effects on the survival, growth, and functioning of other species. ${ }^{1,4,5}$ Allelopathic plant-plant and plant-microbe interactions may be involved in structuring plant communities ${ }^{6}$ and facilitating the invasion of non-native plant species that release unfamiliar compounds in the invaded habitat. ${ }^{6-8}$ Many different types of allelopathic compounds have been isolated and identified in grasses, ${ }^{9,10}$ although the specific modes of action in the affected organisms are often unknown. $1,11,12$, but see 5 In their recent systematic review of allelopathy research in grasslands, Silva et $a l .{ }^{13}$ found that the overwhelming majority of studies reported negative allelopathic effects, indicating that allelopathy may be common in grassland ecosystems.

A number of cool-season pooid grasses have been introduced from their native ranges in southern Europe, northern Africa, and central Asia to new ranges in Oceania and the Americas for use in pasture, forage, and turf applications. Two such grasses, Lolium perenne (perennial ryegrass) and Schedonorus arundinaceus (tall fescue), have a long history of use in New Zealand and USA, respectively. ${ }^{14-16}$ Although these grasses are valued for maintaining productive and persistent pastures in their introduced ranges, livestock consuming them can experience a variety of health issues such as neurological and muscular disorders, decreased weight gain, and reproductive and thermoregulatory difficulties on some pastures but not on others. ${ }^{17-19}$ These illnesses are related to the presence of species-specific symbiotic fungal endophytes of the genus Epichloë (formerly Neotyphodium) in the aboveground tissues of asymptomatic grasses: E. festucae var. lolii in L. perenne and E. coenophiala in S. arundinaceus. The fungi produce a number of herbivore-deterrent alkaloids, some of which are associated with livestock illnesses and others with herbivorous insect and nematode deterrence. ${ }^{17,20-23}$

Shortly after livestock illnesses were linked to the presence of Epichloë endophytes in the host grasses in USA, ${ }^{19}$ researchers in New Zealand were noting reductions in legume abundance (typically Trifolium spp. clovers, often T. repens) in pastures where legumes were co-sown with endophyte-infected L. perenne. They suggested that legume decreases might be linked to alkaloids or other allelochemicals produced by the Epichloë symbiont or induced in the host grass. ${ }^{18,24-27}$ Initial published laboratory assays of Epichloë-related allelopathy in L. perenne had mixed results, however, ranging from negative or no effects to positive allelopathic effects of the endophyte. ${ }^{24,28-31}$ Subsequent examinations of Epichloë-related allelopathy in L. perenne and other species also varied in their detection of allelopathic effects, ${ }^{\text {e.g., }}{ }^{32-34}$ although some variation could be due to differences in study methodologies (e.g., target plant species, response variables measured). Some evidence suggests that Epichloë effects on target plants may be indirect, via soil 


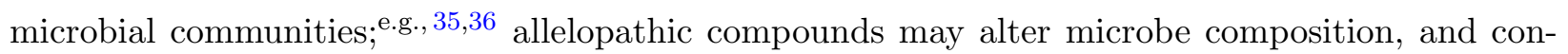
versely, soil microbes may transform or moderate allelochemical effects. ${ }^{3,37}$ Despite the diversity of results to date, Epichloë-related allelopathy continues to be suggested as an explanation for poorer plant performance in the presence of infected than uninfected host grasses and is used as an example of endophyte-driven allelopathy. e.g., 38,39

Epichloë species and strains differ in the main types of alkaloids they produce; ${ }^{40,41}$ for example, the "common" E. festucae var. lolii strain, Lp19, produces ergovaline, peramine, and lolitrem $\mathrm{B},{ }^{42}$ whereas that of E. coenophiala (unnamed) produces ergovaline, peramine, and lolines. ${ }^{43}$ The discovery of ergovaline and lolitrem B as the main causes of livestock toxicity led to the search for Epichloë strains that produce only invertebrate-deterring alkaloids, and various E. festucae var. lolii and E. coenophiala strains are now available commercially in their host grass cultivars. ${ }^{44-46}$. Endophyte strain affects multiple characteristics in the host grass, including alkaloid profiles, ${ }^{42,47}$ volatile organic compound quantities, ${ }^{48}$ root exudate chemical composition, ${ }^{49,50}$ metabolite profiles, ${ }^{51,52}$ and protein production. ${ }^{52}$ Thus, host grasses from the same genetic background but with different Epichloë strains may differ in their allelopathic effects, if such effects occur.

We performed an experiment and a meta-analysis to examine the evidence for allelopathic effects of Epichloë endophytes. Using a greenhouse experiment, we examined the allelopathic effect of four Epichloë festucae var. lolii strains in L. perenne cv. Alto on native North American grassland forbs and legumes and the introduced legume Trifolium repens. We hypothesized that endophyte presence in the host grass would result in negative allelopathic effects on the target plants and that endophyte strains would differ in their effects. We predicted lower biomass in target plants watered with root exudates from Epichloë-containing hosts than from endophyte-free hosts, with differences among Epichloë strains. We then used meta-analysis to synthesize the evidence to date for allelopathic effects on target plants due to Epichloë spp. in cool-season host grasses. We expected that endophyte presence in the host grasses would correspond with negative allelopathic effects on target plants. We also evaluated the effects of methodological differences among studies, specifically: host-endophyte pair, target plant functional group and species, method of target plant exposure to potential allelopathic substances, and substrate microbial status (sterile or inoculated). In all cases, we isolated the endophyte effect by using data on the allelopathic effect of grass hosts from the same genetic background (cultivar) with and without the endophyte.

\section{Methods}

\subsection{Root exudate collection}

Seeds of Lolium perenne L. cv. Alto that were endophyte-free or infected with one of four $E$. festucae var. lolii (Latch, M.J. Chr. \& Samuels) C.W. Bacon \& Schardl endophyte strains (AR1, AR37, NEA2, or Lp19) were provided by Agriseeds (Christchurch, New Zealand). Endophyte presence in seeds was confirmed using an immunoblot assay (Phytoscreen seed endophyte detection kit; Agrinostics, Watkinsville, Georgia, USA). Seeds were individually germinated and grown in 
rockwool medium (Grodan, Roermond, The Netherlands) for six weeks and then transferred to ceramic pots. Plants were then grown hydroponically for several weeks under greenhouse conditions of $\sim 40 \%$ relative humidity, $23^{\circ} \mathrm{C}$, and $16: 8 \mathrm{~h}$ light:dark cycle. Pots were replenished daily with an all-purpose high-nitrate nutrient solution (20-8-20) and adjusted as necessary to maintain $\mathrm{pH}=6$. Once sufficient root volume was obtained, we began collecting root exudate solution. Plants that had been growing in nutrient solution for at least $24 \mathrm{~h}$ were transferred into new pots containing deionized water for $24 \mathrm{~h}$ and then returned to pots containing nutrient solution. The deionized water containing root exudates was collected and filtered using $25-\mu \mathrm{m}$ mesh to remove particulates. The procedure was repeated over a period of $6 \mathrm{wk}$ to collect sufficient exudate solution for the experiment. Exudate solutions from plants containing the same endophyte strain were pooled and stored at $4{ }^{\circ} \mathrm{C}$ until they were used in the experiment $(\sim 72 \mathrm{~L})$.

\subsection{Experimental setup}

We used 11 native and one introduced grassland plant species as target plants: six perennial forbs from the family Asteraceae (Achillea millefolium, Coreopsis lanceolata, Echinacea purpurea, Gaillardia aristata, Kuhnia eupatorioides [=Brickellia], and Ratibida pinnata) and six perennial legumes from the family Fabaceae (Baptisia alba, Dalea purpurea, Desmodium canadense, Glycyrrhiza lepidota, Lupinus perennis, and Trifolium repens). Seeds were obtained from Wildflower Farm (Coldwater, Ontario, Canada), Prairie Moon Nursery (Winona, Minnesota, USA), or Home Hardware (Ontario, Canada; Trifolium only). Prior to planting, seeds of two legume species (Lupinus and Baptisia) were cold-stratified for 10 days according to the supplier's planting instructions. No rhizobacteria were applied to legumes, except for Trifolium, which came pretreated.

Healthy seeds (not discolored or visibly damaged) of each target plant species were potted into seedling trays containing untreated Sunshine \#4 potting mix (Canadian Sphagnum peat moss, coarse perlite, and dolomitic limestone; Sun Gro Horticulture, Agawam, Massachusetts, USA) and germinated in the greenhouse. Greenhouse conditions were 16:8 h light:dark (supplemented for $\geq 500 \mu \mathrm{mol} \mathrm{m} \mathrm{s}^{-1}$ ), $23{ }^{\circ} \mathrm{C}$, and $\sim 10 \%$ relative humidity. Once the first leaf had emerged, 25 seedlings of each species were repotted individually into $1.3 \mathrm{~L}(10 \times 10 \times 13 \mathrm{~cm})$ pots filled with the same potting soil, and 5 replicate seedlings of each species were randomly assigned to each exudate source (endophyte strain).

Five blocks were established on the greenhouse bench to account for a potential light gradient, and the five exudate sources and 12 target species were randomized within blocks, for a total of 300 pots. Each pot received reverse osmosis water in the first three days after repotting. From the fourth day onward, each pot received $50 \mathrm{~mL}$ of exudate solution every second day for the duration of the experiment ( 24 applications total $=1.2 \mathrm{~L} /$ pot over $7 \mathrm{wk}$ ). Reverse osmosis water was supplemented on non-exudate days if needed to maintain moist but not wet soil. Two days after the final exudate application, target plants were harvested, separated into shoot and root biomass, and dried to constant mass at $55^{\circ} \mathrm{C}$. 

available under aCC-BY-NC-ND 4.0 International license.

\begin{tabular}{lccl} 
Response & Effect sizes & Studies & Models $^{a}$ \\
\hline Shoot biomass & 133 & 12 & M, RE, RA \\
Root biomass & 121 & 9 & M, RE, RA \\
Total biomass & 120 & 8 & M, RE, RA \\
Germination or emergence (\%) & 58 & 5 & RE, RA \\
Shoot length & 50 & 3 & RE, RA \\
Root length & 39 & 5 & RE, RA \\
Leaves/plant & 20 & 2 & RE, RA \\
Root hair density & 15 & 1 & RE, RA \\
Root hair length & 15 & 1 & RE, RA \\
Nodulation score & 9 & 2 & $*$ RE, RA \\
Floral biomass & 7 & 2 & RE, RA \\
Total arbuscules + vesicles & 4 & 2 & $*$ RE, RA, SM \\
Arbuscule numbers & 4 & 2 & RE, RA, SM \\
Vesicle numbers & 4 & 2 & $*$ RE, RA, SM \\
\hline
\end{tabular}

Table 1: Meta-analytical models fitted to each response variable. Bold font indicates which model results are shown in the text. All model results are provided in the Supplemental Materials (Online Resource 1). ${ }^{a} \mathrm{M}=$ multilevel random- and mixed-effects models, $\mathrm{RE}=$ random- and mixed-effects models using standard method, RA = random- and mixed-effects models with Hartung-Knapp adjustment to the confidence interval, $\mathrm{SM}=$ small-k analysis (comparing composite effect estimates with individual effects). An asterisk indicates that model results differed on whether the effect estimate's $95 \%$ confidence intervals encompassed 0; otherwise, model results were in agreement. For nodulation score, the effect estimate was significant (positive) for the RE analysis, but the fail-safe number was 1.

\subsection{Statistical analysis}

We used nested analysis of variance to examine the effects of exudate source endophyte strain, target plant functional group, target plant species nested within functional group, and their interactions on shoot, root, and total biomass and shoot:root ratio. Block was treated as a random effect. Significant fixed effects were examined using post-hoc Tukey tests. We used preplanned contrasts to compare target plant growth in exudate applications from endophyte-free vs. endophyte-present Lolium perenne for all species combined and within functional groups. The legume Glycyrrhiza was excluded from analyses involving root and total biomass because of missing root biomass data, and one extreme outlier for Baptisia-AR1 shoot:root ratio was removed. Shoot biomass and shoot:root ratio were $\log 10$-transformed, and root and total biomass were Box-Cox transformed to improve normality of residuals and homogeneity of variance. Analyses were performed in JMP 15 (SAS Institute, Cary, USA).

\subsection{Meta-analysis}

To identify previous studies of Epichloë allelopathic effects on neighbouring plant species, we searched the Web of Science citation index (Clarivate Analytics, Philadelphia, USA) on 20 July 2020 for all times and databases using the topic search: endophyt* AND (allelo* OR feedback) AND (exudate $\mathrm{OR}$ conditioning $\mathrm{OR}$ conditioned $\mathrm{OR}$ extract $\mathrm{OR}$ leach $*$ ), resulting in 63 records. 
Examination of their titles and abstracts resulted in 18 potentially relevant articles for which we read the full text and checked the literature cited for additional studies. Studies were excluded for the following reasons: they compared only cultivars containing the endophyte and did not include an endophyte-free plant control; they compared endophyte-present and endophyte-free plants of different cultivars (i.e., confounded endophyte and cultivar effects); they did not contain the data required to calculate effect sizes (i.e., mean, sample size, and some measure of variance); they were review papers.

From each study, we extracted information about the host plant-endophyte pair and endophyte strain, the target plant species and functional group, target plant exposure method (soil conditioning, root exudates, aqueous tissue extracts, dried plant tissue), and the status of the soil in which target plants were grown (sterilized, live microbial inoculation, or untreated potting soil or filter paper). Because these study characteristics may affect the occurrence and strength of allelopathic effects, we extracted separate means, variance estimates, and sample sizes for each combination. Data were obtained from published tables and figures ${ }^{53}$ or directly from authors. We also included our data from the greenhouse experiment. The complete experimental and meta-analytical data sets are archived at Scholar's Portal Dataverse. ${ }^{54}$ Effect sizes were calculated as the standardized mean difference (Hedges' g) using the escalc() function in the metafor package ${ }^{55}$ in $\mathrm{R}$ version 4.0.2 ( $\mathrm{R}$ Core Team 2020) such that positive and negative effect sizes indicate positive and negative allelopathic effects of endophyte presence on target plant species, respectively.

We fitted random-effects meta-analytical models for individual response variables using the rma() function in metafor. We used both the standard method and the Hartung-Knapp adjustment to the standard error, and we report the widest $95 \%$ confidence intervals. ${ }^{56}$ For the three response variables with the most studies (Table 1), we also fitted multilevel models using the rma.mv() function in metafor. Effect sizes were nested in study, and both effects were treated as random to account for nonindependence of effect sizes within studies (e.g., due to similar experimental conditions, use of a single control endophyte-free comparison for multiple effects, use of least significant difference when variance was not reported). We note, however, that sample sizes $<10-30$ at the highest cluster level (i.e., study) can inflate type I error rates (i.e., increase false positives $\left.{ }^{57-60}\right)$. We compared the fit of multilevel models with and without each within-study and between-study variance component using log-likelihood-ratio tests ${ }^{60,61}$ to determine whether they explained significant variance, and we used the mlm.variance.distribution() function in dmetar ${ }^{61}$ to calculate the distribution of variance among the random effects. Finally, for responses with $\leq 4$ effect sizes, we examined both composite (random-effects models) and individual effects (Table 1) due to known modelling issues with "small-k" (i.e., few effect sizes) meta-analysis. ${ }^{62}$

All meta-analytical models were fitted using inverse variance weighting and restricted maximum likelihood estimation. Homogeneity of effect sizes and the proportion of heterogeneity not attributable to sampling error were evaluated using Cochran's Q and $\mathrm{I}^{2}$, respectively. Responses that showed significant heterogeneity were examined further using mixed-effects meta-regression models and each of four categorical predictors (moderators: host-endophyte combination, exposure 
method, target plant functional group, and soil status) to determine their moderating effect on the endophyte allelopathic effect. Moderators were fitted individually due to multicollinearity. ${ }^{61}$ All model results are provided in Supplemental Materials (Online Resource 1) for comparison.

To evaluate the potential for research bias, we calculated fail-safe numbers (the number of nonsignificant effect sizes that would be required to make the overall effect nonsignificant) at alpha of 0.05 using the Rosenberg method (Rosenberg 2005) in metafor for effects for which the $95 \%$ confidence intervals did not encompass zero. We note that research bias tests may be unreliable (inflated type I error) due to data nonindependence, and such methods have not yet been extended robustly to multilevel models with moderators. ${ }^{60,63,64}$

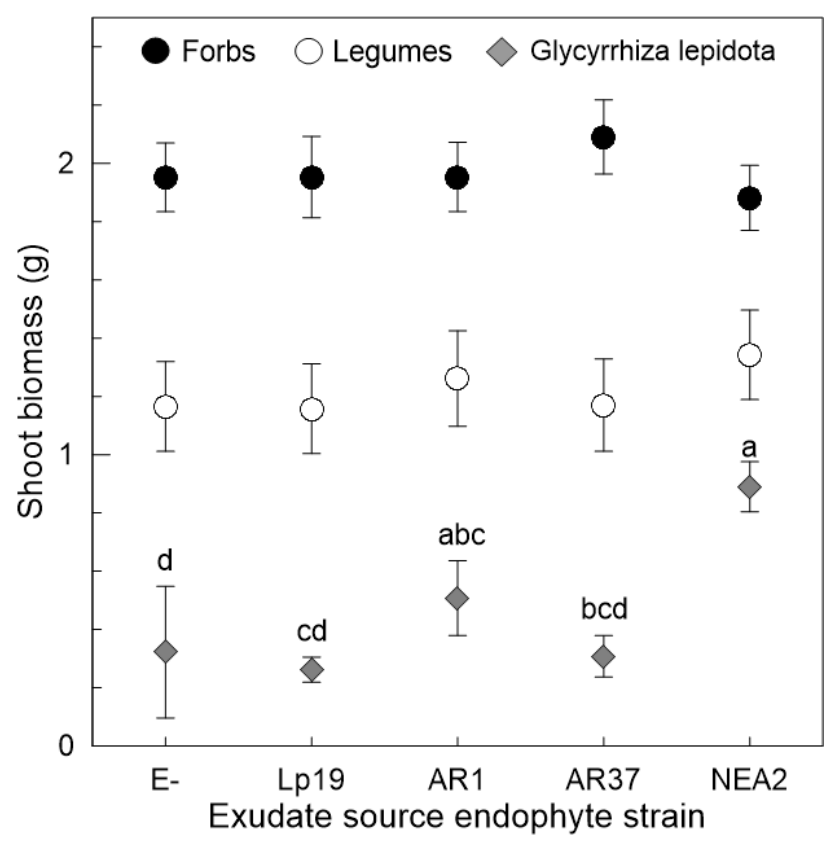

Figure 1: Mean \pm standard deviation of untransformed shoot biomass of forbs, legumes, and the legume Glycyrrhiza lepidota watered with root exudates from Lolium perenne endophyte-free (E-) or infected with one of four Epichloë festucae var. lolii strains.

\section{Results}

\subsection{Greenhouse experiment}

The exudate source endophyte strain differentially affected shoot biomass depending on the target plant species and functional group (significant exudate $\times$ species[functional group] and exudate $\times$ functional group effects; Table 2). Forb shoot biomass did not differ with exudate source. In contrast, legume shoot biomass was greater with NEA2 than endophyte-free exudate (and greater with endophyte-present than endophyte-free exudate; significant contrast, Table 2). This effect was driven by the legume Glycyrrhiza, which was the only species that differed significantly among exudate sources and was highest with NEA2 and AR1 and lowest with endophyte-free exudate (Figure 1). 


\begin{tabular}{|c|c|c|c|c|c|c|c|c|c|c|}
\hline \multirow[b]{2}{*}{ Source } & \multicolumn{4}{|c|}{ Shoot biomass } & \multicolumn{2}{|c|}{ Root biomass } & \multicolumn{2}{|c|}{ Shoot:Root } & \multicolumn{2}{|c|}{ Total biomass } \\
\hline & $d f$ & $F$ & $P$ & $d f^{a}$ & $F$ & $P$ & $F$ & $P$ & $F$ & $P$ \\
\hline Exudate source strain & 4,236 & 2.35 & 0.055 & 4,215 & 0.79 & 0.54 & 1.52 & 0.2 & 0.16 & 0.96 \\
\hline E- vs. E + & 1,236 & 5.16 & 0.024 & 1,215 & 2.91 & 0.09 & 3.92 & 0.049 & 0.19 & 0.67 \\
\hline FctGrp & 1,236 & 393.60 & $<0.0001$ & 1,215 & 741.30 & $<0.0001$ & 182.70 & $<0.0001$ & 648.10 & $<0.0001$ \\
\hline Exudate $\times$ FctGrp & 4,236 & 3.69 & 0.006 & 4,215 & 0.43 & 0.79 & 0.12 & 0.97 & 1.12 & 0.35 \\
\hline Forb: E- vs. E+ & 1,236 & 0.02 & 0.88 & 1,215 & 2.65 & 0.11 & 2.09 & 0.15 & 0.39 & 0.53 \\
\hline Legume: E- vs. E+ & 1,236 & 9.37 & 0.003 & 1,215 & 0.68 & 0.41 & 1.85 & 0.18 & 0.0002 & 0.99 \\
\hline Species(FctGrp) & 10,236 & 89.95 & $<0.0001$ & 9,215 & 68.87 & $<0.0001$ & 33.12 & $<0.0001$ & 125.30 & $<0.0001$ \\
\hline Exudate $\times$ Species $($ FctGrp $)$ & 40,236 & 2.74 & $<0.0001$ & 36,215 & 0.87 & 0.68 & 0.95 & 0.55 & 1.18 & 0.23 \\
\hline
\end{tabular}

Table 2: ANOVA results for effects of root exudates from Lolium perenne infected with different endophyte strains or no endophyte on growth responses of six native legume species (five legume species for measures involving root biomass) and six native forb species. Endophyte-free (E-) vs. endophyte-present $(\mathrm{E}+)$ contrasts are highlighted in grey. FctGrp $=$ functional group (forb or legume). Highlighted rows are contrasts. Shoot biomass and shoot:root ratio were $\log 10$ transformed, and root and total biomass were Box-Cox transformed. ${ }^{a}$ Shoot:root $d f$ error $=214$. 
Root biomass, shoot:root ratio, and total biomass were mostly unaffected by the exudate source. Only shoot:root ratio was greater with endophyte-present than endophyte-free exudate sources (significant contrast), but the effect was very small. Unsurprisingly, all growth measures differed by target plant species and functional group (significant species[functional group] and functional group effects; Table 2). Forbs generally produced more shoot, root, and total biomass and had lower shoot:root ratios than legumes (not shown).

\subsection{Meta-analysis}

Twelve articles were both relevant and had data that could be extracted from figures or tables or obtained from the authors. ${ }^{24,30,32-36,65-69}$ Four additional papers ${ }^{28,29,31,70}$ and one thesis ${ }^{71}$ identified from the references and our knowledge of the literature also had relevant extractable or obtainable data. Data from these 17 sources and our greenhouse experiment provided 603 effect sizes.

Data were obtained for 17 response variables. Two responses with one effect size each (stolons per plant and plant vigour score), and one response with two effect sizes (arbuscle:vesicle ratio), were excluded from further analysis. The remaining responses each had $\geq 4$ effect sizes and were examined meta-analytically (599 effect sizes analysed). There were 41 target plant species: 12 legumes, including six Trifolium species; 11 forbs; nine trees; and nine grasses, including four of the host grasses (considered as selfE + and selfE- functional groups when source and target plant species were the same, i.e., autoallelopathy, and the target plant did or did not host the endophyte, respectively). Four exposure methods were used: "aqueous extracts" obtained by soaking dried host-grass tissue in water; "dried host-plant tissue" applied directly on or in the soil; "root exudates" collected from the host grass; and "soil conditioning" by growing and removing the host-grass from soil that was then planted with the target plant. Finally, five host-endophyte pairs (all having strictly vertical endophyte transmission) were examined: Festuca rubra-E. festucae (48 effect sizes, one study), Lolium multiflorum-E. occultans (46 effect sizes, four studies), Lolium perenne-E. festucae var. lolii (287 effect sizes, eight studies), Schedonorus arundinaceus-E. coenophiala (205 effect sizes, five studies), and Schedonorus pratensis-E. uncinata (13 effect sizes, two studies).

Meta-analysis showed negative effects of Epichloë presence-related allelopathy on target plant root hair density and root hair length (Figure 2A). Both effects were large (>0.8; Cohen 1988), with large fail-safe numbers, and the low $\mathrm{I}^{2}$ values $(<40 \%)$ suggest that effect size heterogeneity has minimal importance. ${ }^{72}$ However, all effect sizes were from a single study. In contrast, there was a small (0.2) positive allelopathic effect on target plant shoot biomass (Figure 2A), with a large fail-safe number. Although the heterogeneity test was statistically significant (Q132 = 181.78, $P=0.003)$, likely due to the large number of effect sizes, the low $\mathrm{I}^{2}$ suggests that its importance is minimal.

All other target plant responses showed no effect of Epichloë presence-related allelopathy, i.e., their $95 \%$ confidence intervals encompassed zero. Despite the positive allelopathic effect on shoot biomass, neither total nor root biomass showed a response (Figure 2A). Similar to shoot biomass, total and root biomass had statistically significant heterogeneity (total: Q119 = 204.31, $P<0.001$; 
bioRxiv preprint doi: https://doi.org/10.1101/2021.11.10.468080; this version posted November 13,2021 . The copyright holder for this preprint (which was not certified by peer review) is the author/funder, who has granted bioRxiv a license to display the preprint in perpetuity. It is made available under aCC-BY-NC-ND 4.0 International license.

Hager et al.

Allelopathic effects of Epichloë fungal endophytes



\section{(B)}

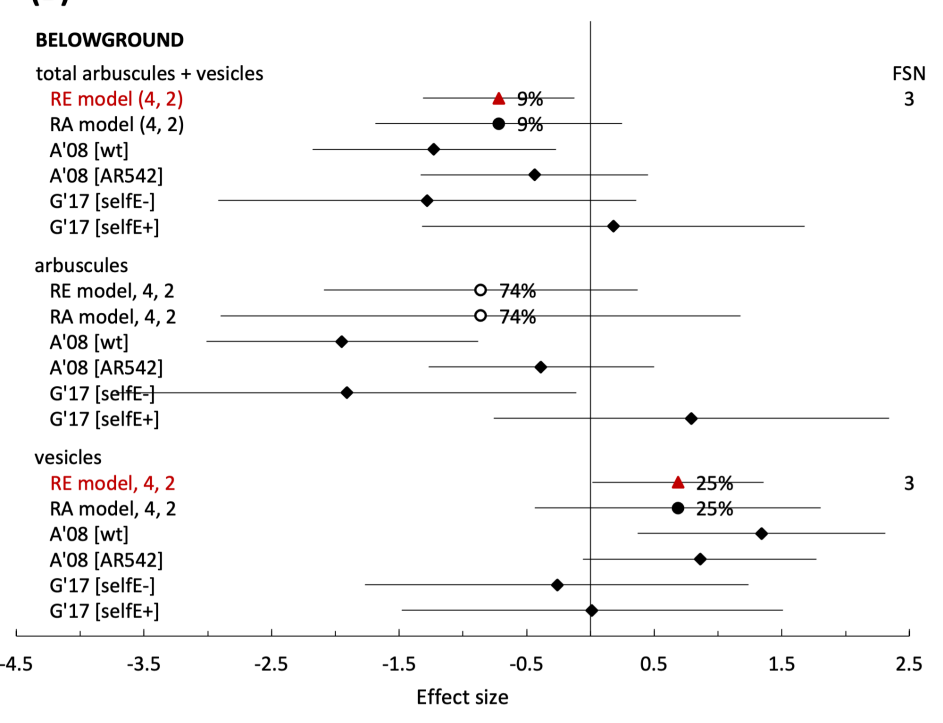

Figure 2: Overall target-plant responses to allelopathy due to the presence of Epichloe endophyte in its host grass. (A) Responses with 7-120 effect sizes. Points and whiskers are effect sizes and $95 \%$ confidence intervals, respectively. Numbers of effect sizes and studies are in parentheses. Point labels are $\mathrm{I}^{2}$ values (proportion of heterogeneity not attributable to sampling error). Dark red triangles $=$ significant composite effects, circles = nonsignificant composite effects, hollow symbols = significant heterogeneity of effect sizes (Cochran's Q). FSN = fail-safe numbers (number of nonsignificant effect sizes required to make the overall effect nonsignificant). (B) Responses with four effect sizes. Symbols as in (A) and diamonds = single effect sizes. A'08 = Antunes et al. 2008, ${ }^{35}$ G'17 = Garcia-Parisi and Omacini 2017, ${ }^{65}$ and brackets indicate treatment differences: wt and AR542 are different endophyte strains; selfE - and selfE+ indicate that target plants were the same species as the host grass and did not or did host the endophyte, respectively. See Table 1 for associated model information. 
root: $\mathrm{Q} 120=176.28, P<0.001$ ), with their $\mathrm{I}^{2}$ values suggesting low (root biomass) to moderate (total biomass) importance of effect size heterogeneity. ${ }^{72}$ Target plant floral biomass, number of leaves per plant, \%-germination or -emergence, and nodulation score all had nonsignificant effect size heterogeneity, although the $\mathrm{I}^{2}$ value for leaves/plant (40\%) suggests that heterogeneity might still be considered low to moderate. In contrast, shoot and root length had significant moderate to substantial effect size heterogeneity $\left(\mathrm{Q} 49=87.22, P<0.001, \mathrm{I}^{2}=41 \%\right.$ and $\mathrm{Q} 38=111.00$, $P<0.001, \mathrm{I}^{2}=67 \%$, respectively). For small-k responses (Figure $2 \mathrm{~B}$ ), the standard and adjusted random effects models differed in their detection of allelopathic effects for total arbuscule + vesicle numbers and vesicle numbers. However, fail-safe numbers were very low, and the individual studies showed no consistency in the direction of effects, suggesting that these models are not robust. Effect sizes for arbuscule numbers were highly heterogeneous.

None of the study design moderators were significant explanatory covariates of shoot biomass effect size (meta-regressions, Figure 2A). The lack of significance may be due to small sample sizes for some subgroups. However, small to moderate positive allelopathic responses were found for legumes, target plants treated with dried plant tissue, target plants in sterilized substrate, and those treated with substances from the L. perenne-E. festucae var. lolii host-endophyte combination. Application method and soil status were significant moderators of target plant root biomass responses to allelopathy (Figure 2B), with small and moderate positive responses for target plants treated with dried plant tissue and those in sterilized substrate, respectively. Neither target plant functional group nor the host-endophyte combination were significant moderators of target plant root biomass. Total biomass responded similarly to root biomass, although only the soil status moderator was statistically significant (see Online Resource 1). Finally, none of the moderators were significant explanatory covariates of shoot or root length, and none of the subgroup effect sizes differed from zero (Online Resource 1). Significant residual heterogeneity remained after accounting for moderators for all response variables.

\section{Discussion}

In our experiment and meta-analytical synthesis, we focused specifically on allelopathic effects due to the presence of the mutualist Epichloë endophyte in its grass host. Contrary to what has generally been hypothesized for these host-specific symbionts, we found very little evidence overall for negative allelopathic effects on other plants across a range of methodologies, target plant species, and response measures. Significant negative allelopathic effects were detected only for root hair measures, whereas positive effects were found for shoot, root, and total biomass in some experimental subgroups. The majority of response variables showed no evidence for allelopathy due to the presence of Epichloë. We also detected little allelopathy of, and few differences among, Epichloë festucae var. lolii strains.

The negative allelopathic effects detected for root hair density and length are based on multiple effect sizes from one study examining one legume genus (Trifolium spp.), using seeds that were 
bioRxiv preprint doi: https://doi.org/10.1101/2021.11.10.468080; this version posted November 13,2021 . The copyright holder for this preprint (which was not certified by peer review) is the author/funder, who has granted bioRxiv a license to display the preprint in perpetuity. It is made available under aCC-BY-NC-ND 4.0 International license.

Hager et al.

Allelopathic effects of Epichloë fungal endophytes
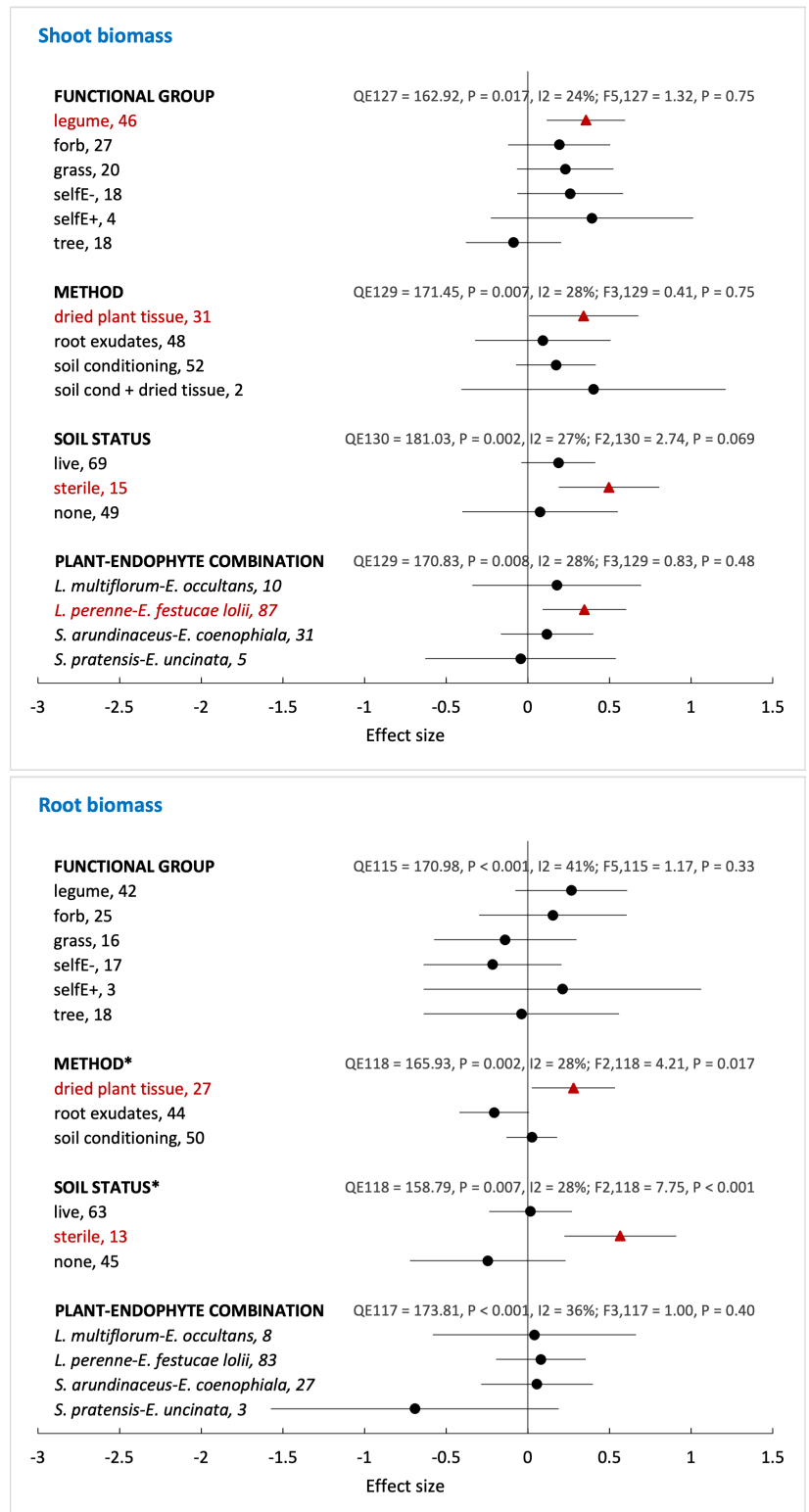

Figure 3: Effects of four moderators on target-plant responses to allelopathy due to the presence of Epichlö̈ endophyte in its host grass for shoot biomass (A) and root biomass (B). Moderator test statistics are residual heterogeneity $(\mathrm{QE})$ and its significance, proportion of heterogeneity not attributable to sampling error $\left(\mathrm{I}^{2}\right)$, and omnibus $F$-test of moderator effect and its significance. Asterisk indicates significant moderator effect based on the omnibus test. Subgroup labels are followed by numbers of effect sizes. Points and whiskers are effect sizes and 95\% confidence intervals, respectively. Dark red triangles = significant effects, black circles $=$ nonsignificant effects 
grown for seven days on filter paper. ${ }^{6}$ Thus, we do not know whether this result is replicable. Given that root hairs are involved in water and nutrient uptake and are the site of rhizobial infection and nodule formation in legumes, ${ }^{73}$ their reduction could negatively affect subsequent plant growth. However, the lack of allelopathic effects for root nodulation and legume root biomass and length, and the positive effect for legume shoot biomass, suggest that either Springer's findings ${ }^{66}$ are anomalous or early changes to root hairs have negligible effects on subsequent plant growth. Microscopic examination for damage or changes at the cellular level may better indicate the mechanisms and consequences of the potential interaction. ${ }^{5}$

The overall positive effects on shoot biomass found for legumes and the L. perenne-E. festucae var. lolii pair suggest that Epichloë allelopathy is an unlikely mechanism explaining observations of poorer clover growth in endophyte-infected than uninfected L. perenne pastures. Experiments have shown that $\mathrm{T}$. repens persistence in mixed pastures with $L$. perenne is affected by water availability, ${ }^{27,74}$ nitrogen fertilization level, ${ }^{75,76}$ and grazing or mowing regime, ${ }^{77,78}$ which influence competitive ability. Additionally, the Epichloë symbiosis can have various ecosystem effects ${ }^{79}$ by altering resource competition, ${ }^{80}$ herbivore and pathogen pressure, ${ }^{81}$ and decomposition rates. ${ }^{82,83 ;}$ but see 84 These differences likely influence host-grass competitive outcomes in plant communities.

Epichlö̈ presence in host grasses may alter soil microbial and invertebrate community composition as well as colonization of the host grass by arbuscular mycorrhizal and dark septate fungi, although studies do not always agree on the direction of effects. ${ }^{83,85-90}$ Although some studies have suggested the possibility of negative plant-soil feedbacks to the infected host grass due to Epichloë, ${ }^{68,91}$ there were too few samples from the literature to determine whether Epichloë allelopathy might be involved (selfE+: $N=4$ and 3 for shoot and root biomass, respectively); such allelopathy does not appear to affect the endophyte-free host grass. Rojas et al. ${ }^{92}$ noted that reductions in certain soil fungal genera with Epichloë presence in the grass host might indicate protective effects against plant pathogens, which could also benefit neighbouring plants. Soil microbes might also alleviate negative effects by metabolizing or transforming allelopathic substances. ${ }^{93}$ One then might expect to see a more positive Epichloë allelopathic effect on target plant biomass in live soils than in sterilized soils. However, our meta-analysis detected a positive effect in sterilized soils and no effect in live soils for shoot and root biomass. Experiments testing the functional belowground effects of Epichloë presence ${ }^{\text {e.g., } 94}$ may be fruitful in clarifying how the endophyte affects neighbouring plant performance via plant-soil feedbacks. ${ }^{39,95}$ Currently, there are insufficient measurements to draw conclusions about how Epichloë allelopathy affects arbuscular mycorrhizal fungal colonization of non-host plants, and there are no measures of effects on other microbes.

Although metabolite profiles of $L$. perenne root exudates differ among the endophyte strains we used in the greenhouse experiment, ${ }^{50}$ strains neither differed in allelopathic effects nor had a detectable effect on target plant biomass overall. Although we detected different effects for the legume Glycyrrhiza lepidota, and the direction was positive for two strains (AR1 and NEA2) compared to endophyte-free root exudates, the result is likely not biologically significant due to poor growth of this species during the experiment, possibly because it lacked its rhizobial symbiont. Limited data 
from the literature prevented meta-analytical comparisons among endophyte strains and among host plant genetic backgrounds (cultivars). We note that studies comparing Epichloë coenophiala strains in $S$. arundinaceus found few differential effects on potential sources of indirect plant-soil feedbacks: soil nitrogen fixation, ${ }^{90}$ arbuscular mycorrhizal and dark septate fungal colonization of the host grass, ${ }^{89}$ or soil nutrients and function, with the exception of carbon. ${ }^{49}$

It is difficult to evaluate adequately the true effect of bias in meta-analyses, particularly when effect sizes are heterogeneous and non-independent. ${ }^{63,64,96}$ One source of bias occurs when nonsignificant results are not published (i.e., publication bias or selective reporting). In our case, we were unable to obtain data from a few early studies, but we were able to obtain some unpublished data. Given the minimal number of significant effects in our meta-analysis, we do not think selective reporting was a major issue. In contrast, research bias could be problematic. For example, we only found Epichloë allelopathy studies for five host-endophyte pairs, all of which are well-studied agronomic grasses. In contrast, the most recent Epichloë taxonomic revision recognizes 29 distinct lineages (species, subspecies, and varieties) with strictly vertical transmission and 14 lineages with horizontal or both modes of transmission. ${ }^{97,98}$ Inferences from our meta-analysis may not extend to non-agronomic or horizontally transmitted Epichloë endophytes. Additionally, effect size data for many potentially important response measures were limited (e.g., nodulation, arbuscular mycorrhizal colonization, floral biomass, root hair characteristics) or nonexistent (e.g., seed production, survival, fitness, microbial activity).

The absence of Epichlö allelopathy contrasts the weight of evidence for allelopathy in grassland species, reviewed by Silva et al. ${ }^{13}$ where $73 \%$ of studies reported inhibitory allelopathic effects, and a further $\sim 22 \%$ reported both inhibitory and stimulatory effects. see also ${ }^{38}$ Thus, the host grass species may have allelopathic effects on neighbouring plants, regardless of Epichloë presence, which we did not examine. Hodge and Fitter ${ }^{99}$, p. 867 note that the interpretation of plant-soil feedback studies "requires caution" because experimental conditions can be somewhat artificial, lacking community context, and potentially affecting the persistence and activity of allelochemicals. ${ }^{5}$ Nevertheless, current evidence suggests that Epichloë allelopathy is unlikely to be a source of strong influence for suppressing neighbouring plant species or facilitating invasion of the host grasses into novel ecosystems.

Acknowledgements: This research was conducted on the ancestral lands of the Neutral, Anishnaabe, and Haudenosaunee peoples, and more recently, on the treaty lands and territory of the Mississaugas of the Credit First Nation. We recognize that today this gathering place is home to many First Nations, Inuit, and Métis peoples, and acknowledging them reminds us of our collective responsibility to the land where we learn and work, and to the on-going efforts for reconciliation. We gratefully acknowledge the assistance of N. Charlton, Z. Gedalof, several student volunteers, and the University of Guelph Phytotron staff. We thank C. Inch for providing the Lolium perenne seed and A. Patchett for hydroponics design. We also thank the authors who directly provided us their raw or summarized data for the meta-analysis. 
Data availability: The complete experimental and meta-analytical data sets are archived at: Hager HA, Gailis M, Newman JA (2021) Allelopathic effects of Epichloë fungal endophytes: experiment and meta-analysis. [data set] Scholars Portal Dataverse. https://doi.org/10.5683/SP3/VF5XWU

Author contributions: Designed the experiment: HAH; performed greenhouse experiment: MG, HAH; performed meta-analysis: HAH; analysed data: HAH; wrote manuscript: HAH; edited manuscript: $\mathrm{HAH}, \mathrm{JAN}, \mathrm{MG}$

\section{References}

[1] FA Einhellig. Allelopathy: current status and future goals. In Dakshini K M M Inderjit and F A Einhellig, editors, Allelopathy: organisms, processes, and applications.

[2] C Bertin, X Yang, and LA Weston. The role of root exudates and allelochemicals in the rhizosphere. Plant and Soil, 256(1):67-83, 2003.

[3] DKMM Inderjit. Soil microorganisms: an important determinant of allelopathic activity. Plant and Soil, pages 227-236, 2005.

[4] JC Reese. Interactions of allelochemicals with nutrients in herbivore food. In GA Rosenthal and DH Janzen, editors, Herbivores: Their Interaction With Secondary Plant Metabolites, pages 309-330. Academic Press, New York, New York, USA, 1979.

[5] F Cheng and Z Cheng. Research progress on the use of plant allelopathy in agriculture and the physiological and ecological mechanisms of allelopathy. Frontiers in Plant Science, 6:1020, 2015 .

[6] DA Wardle, R Karban, RM Callaway, et al. The ecosystem and evolutionary contexts of allelopathy. Trends in Ecology \& Evolution, 26(12):655-662, 2011.

[7] RM Callaway and WM Ridenour. Novel weapons: invasive success and the evolution of increased competitive ability. Frontiers in Ecology and the Environment, 2(8):436-443, 2004.

[8] MN Uddin, T Asaeda, SH Shampa, and RW Robinson. Allelopathy and its coevolutionary implications between native and non-native neighbors of invasive Cynara cardunculus l. Ecology and Evolution, 10(14):7463-7475, 2020.

[9] AM Sánchez-Moreiras, OA Weiss, and MJ Reigosa-Roger. Allelopathic evidence in the poaceae. The Botanical Review, 69(3):300-319, 2003.

[10] A Favaretto, SM Scheffer-Basso, and NB Perez. Allelopathy in Poaceae species present in Brazil. A review. Agronomy for Sustainable Development, 38(2):1-12, 2018. 
[11] M Wink and B Latz-Brüning. Allelopathic properties of alkaloids and other natural products: possible modes of action. In DKMM Inderjit and FA Einhellig, editors, Allelopathy: Organisms, Processes, and Applications, pages 1-24. American Chemical Society, Washington, D.C., 1995.

[12] HP Bais, TL Weir, LG Perry, S Gilroy, and JM Vivanco. The role of root exudates in rhizosphere interactions with plants and other organisms. Annual Review Plant Biology, 57:233-266, 2006.

[13] ER da Silva, GE Overbeck, and GLG Soares. Something old, something new in allelopathy review: what grassland ecosystems tell us. Chemoecology, 27(6):217-231, 2017.

[14] CS Hoveland. Agronomic performance of New Zealand pastures: implications of Acremonium presence. In DE Hume, GCM Latch, and HS Easton, editors, Proceedings of the Second International Symposium on Acremonium/Grass Interactions: Plenary Papers, pages 31-38. AgResearch Grasslands Research Centre, Palmerston North, New Zealand, 1993.

[15] AV Stewart. Genetic origins of perennial ryegrass (Lolium perenne) for New Zealand pastures. In CF Mercer, editor, Proceedings of the $13^{\text {th }}$ Australasian Plant Breeding Conference, pages 11-20. New Zealand Grassland Association, Dunedin, New Zealand, 2006.

[16] JK Rogers and JM Locke. Tall Fescue: History, Application, Establishment and Management. Samuel Roberts Noble Foundation, Ardmore, Oklahoma, USA, 2013.

[17] CL Schardl. Epichloë species: fungal symbionts of grasses. Annual Review of Phytopathology, 34(1):109-130, 1996.

[18] HS Easton, MJ Christensen, JPJ Eerens, LR Fletcher, DE Hume, RG Keogh, GA Lane, GCM Latch, CGL Pennell, AJ Popay, et al. Ryegrass endophyte: a New Zealand grassland success story. Proceedings of the New Zealand Grassland Association, pages 37-46, 2001.

[19] CS Hoveland. Origin and history. In HA Fribourg, DB Hannaway, and CP West, editors, Tall Fescue for the Twenty-First Century, pages 1-24. ASA, CSSA, SSSA, Madison, Wisconsin, USA, 1995.

[20] MC Johnson, DL Dahlman, MR Siegel, LP Bush, GCM Latch, DA Potter, and DR Varney. Insect feeding deterrents in endophyte-infected tall fescue. Applied and Environmental Microbiology, 49(3):568-571, 1985.

[21] RA Prestidge, DR Lauren, SG Van Der Zijpp, and ME Di Menna. Isolation of feeding deterrents to Argentine stem weevil in cultures of endophytes of perennial ryegrass and tall fescue. New Zealand Journal of Agricultural Research, 28(1):87-92, 1985.

[22] CA Kimmons, KD Gwinn, EC Bernard, et al. Nematode reproduction on endophyte-infected and endophyte-free tall fescue. Plant Disease, 74(10):757-761, 1990. 
[23] MR Siegel, GCM Latch, LP Bush, FF Fannin, DD Rowan, BA Tapper, CW Bacon, and MC Johnson. Fungal endophyte-infected grasses: alkaloid accumulation and aphid response. Journal of Chemical Ecology, 16(12):3301-3315, 1990.

[24] BL Sutherland and JH Hoglund. Effect of ryegrass containing the endophyte Acremonium lolii on associated white clover. In SS Quisenberry and RE Joost, editors, Proceedings of the First International Symposium on Acremonium/Grass Interactions, pages 67-71. Louisiana Agricultural Experiment Station, Baton Rouge, Louisiana, USA, 1990.

[25] RN Watson. Effects of plant nematodes and Acremonium endophyte on white clover establishment with ryegrass or tall fesuce. In Proceedings of the Forty Third New Zealand Weed and Pest Control Conference, pages 347-351. New Zealand Weed and Pest Control Society, Palmerston North, New Zealand, 1990.

[26] PJ Cunningham, JZ Foot, and KFM Reed. Perennial ryegrass (Lolium perenne) endophyte (Acremonium lolii) relationships: the Australian experience. Agriculture, Ecosystems $\&$ Environment, 44(1-4):157-168, 1993.

[27] JPJ Eerens, RJ Lucas, HS Easton, and JGH White. Influence of the ryegrass endophyte (Neotyphodium lolii) in a cool moist environment. I. Pasture production. New Zealand Journal of Agricultural Research, 41(1):39-48, 1998.

[28] PE Quigley, FJ Snell, PJ Cunningham, and W Frost. The effects of endophyte infected ryegrass on the establishment, persistence and production of mixed pastures in Australia. In SS Quisenberry and RE Joost, editors, Proceedings of the First International Symposium on Acremonium/Grass Interactions, pages 49-51. Louisiana Agricultural Experiment Station, Baton Rouge, Louisiana, USA, 1990.

[29] NM McFarlane, B Jowett, A Schroder, and PE Quigley. Potential harmful effects of high endophyte content in perennial ryegrass on companion legumes. In KJ Hutchinson and PJ Vickery, editors, Proceedings of the $6^{\text {th }}$ Australian Agronomy Conference. Australian Society of Agronomy, Australia, 1992.

[30] RA Prestidge, ER Thom, SL Marshall, MJ Taylor, B Willoughby, and DD Wildermoth. Influence of Acremonium lolii infection in perennial ryegrass on germination, emergence, survival, and growth of white clover. New Zealand Journal of Agricultural Research, 35(2):225-234, 1992.

[31] FJ Snell and PE Quigley. Allelopathic effects of endophyte in perennial ryegrass residues on young subterranean clover plants. In Proceedings of the XVII International Grassland Congress, pages 343-344. New Zealand Grassland Association, Palmerston North, New Zealand, 1993. 
[32] JA Rudgers and S Orr. Non-native grass alters growth of native tree species via leaf and soil microbes. Journal of Ecology, 97(2):247-255, 2009.

[33] BR Vázquez-de Aldana, M Romo, A García-Ciudad, C Petisco, and B García-Criado. Infection with the fungal endophyte Epichloë festucae may alter the allelopathic potential of red fescue. Annals of Applied Biology, 159(2):281-290, 2011.

[34] MG Cripps, GR Edwards, and SL McKenzie. Grass species and their fungal symbionts affect subsequent forage growth. Basic and Applied Ecology, 14(3):225-234, 2013.

[35] PM Antunes, J Miller, LM Carvalho, JN Klironomos, and JA Newman. Even after death the endophytic fungus of Schedonorus phoenix reduces the arbuscular mycorrhizas of other plants. Functional Ecology, 22(5):912-918, 2008.

[36] C Casas, JP Torretta, N Exeler, and M Omacini. What happens next? Legacy effects induced by grazing and grass-endophyte symbiosis on thistle plants and their floral visitors. Plant and Soil, 405(1):211-229, 2016.

[37] H Kaur, R Kaur, S Kaur, and IT Baldwin. Taking ecological function seriously: soil microbial communities can obviate allelopathic effects of released metabolites. PloS One, 4(3):e4700, 2009 .

[38] H Lipinska and W Harkot. Allelopathic activity of grassland species. Allelopathy Journal, 19(1):3-36, 2007.

[39] D Cipollini, CM Rigsby, and EK Barto. Microbes as targets and mediators of allelopathy in plants. Journal of Chemical Ecology, 38(6):714-727, 2012.

[40] K Clay and C Schardl. Evolutionary origins and ecological consequences of endophyte symbiosis with grasses. The American Naturalist, 160(S4):S99-S127, 2002.

[41] V Vikuk, CA Young, ST Lee, P Nagabhyru, M Krischke, MJ Mueller, and J Krauss. Infection rates and alkaloid patterns of different grass species with systemic Epichloë endophytes. Applied and Environmental Microbiology, 85(17):e00465-19, 2019.

[42] AJ Popay and PJ Gerard. Cultivar and endophyte effects on a root aphid Aploneura lentisci in perennial ryegrass. New Zealand Plant Protection, 60:223-227, 2007.

[43] JE Takach and CA Young. Alkaloid genotype diversity of tall fescue endophytes. Crop Science, 54(2):667-678, 2014.

[44] LR Fletcher, AJ Popay, and BA Tapper. Evaluation of several lolitrem-free endophyte/perennial ryegrass combinations. Proceedings of the New Zealand Grassland Association, pages 215-219, 1991. 
[45] BA Tapper and GCM Latch. Selection against toxin production in endophyte-infected perennial ryegrass. In DR Woodfield and C Matthew, editors, Ryegrass Endophyte: An Essential New Zealand Symbiosis, pages 107-111. New Zealand Grassland Association, Palmerston North, New Zealand, 1990.

[46] J Bouton and S Easton. Endophytes in forage cultivars. In C A Roberts, C P West, and D E Spiers, editors, Neotyphodium in Cool-Season Grasses, pages 327-340. Blackwell, Ames, Iowa, USA, 2005.

[47] MC Soto-Barajas, BR Vazquez-de Aldana, A Álvarez, and I Zabalgogeazcoa. Sympatric Epichloë species and chemotypic profiles in natural populations of Lolium perenne. Fungal Ecology, 39:231-241, 2019.

[48] A Qawasmeh, A Raman, and W Wheatley. Volatiles in perennial ryegrass infected with strains of endophytic fungus: impact on African black beetle host selection. Journal of Applied Entomology, 139(1-2):94-104, 2015.

[49] J Guo, RL McCulley, and DH McNear Jr. Tall fescue cultivar and fungal endophyte combinations influence plant growth and root exudate composition. Frontiers in Plant Science, 6:183, 2015 .

[50] A Patchett and JA Newman. Comparison of plant metabolites in root exudates of lolium perenne infected with different strains of the fungal endophyte Epichloë festucae var. lolii. Journal of Fungi, 7(2):148, 2021.

[51] S Rasmussen, AJ Parsons, and JA Newman. Metabolomics analysis of the lolium perenneNeotyphodium lolii symbiosis: more than just alkaloids? Phytochemistry Reviews, 8(3):535$550,2009$.

[52] J Geddes-McAlister, A Sukumaran, A Patchett, HA Hager, J Dale, JL Roloson, N Prudhomme, K Bolton, B Muselius, J Powers, et al. Examining the impacts of $\mathrm{CO}_{2}$ concentration and genetic compatibility on perennial ryegrass-Epichloë festucae var lolii interactions. Journal of Fungi, $6(4): 360,2020$.

[53] A Rohatgi. Webplotdigitizer. version 4.3. https://automeris.io/WebPlotDigitizer.

[54] HA Hager, M Gailis, and JA Newman. [dataset] allelopathic effects of Epichlö̈ fungal endophytes: experiment and meta-analysis. Scholars Portal Dataverse, 2021. https://doi.org/10.5683/SP3/VF5XWU.

[55] W Viechtbauer. Conducting meta-analyses in $\mathrm{R}$ with the metafor package. Journal of Statistical Software, 36(3):1-48, 2010.

[56] RCM van Aert and D Jackson. A new justification of the Hartung-Knapp method for randomeffects meta-analysis based on weighted least squares regression. Research Synthesis Methods, 10(4):515-527, 2019. 
[57] W Van Den Noortgate and P Onghena. Multilevel meta-analysis: A comparison with traditional meta-analytical procedures. Educational and Psychological Measurement, 63(5):765-790, 2003.

[58] W Van den Noortgate, JA López-López, F Marín-Martínez, and J Sánchez-Meca. Three-level meta-analysis of dependent effect sizes. Behavior Research Methods, 45(2):576-594, 2013.

[59] B Fernández-Castilla, L Jamshidi, L Declercq, SN Beretvas, P Onghena, and W Van den Noortgate. The application of meta-analytic (multi-level) models with multiple random effects: A systematic review. Behavior Research Methods, 52(5), 2020.

[60] Mark Assink, Carlijn JM Wibbelink, et al. Fitting three-level meta-analytic models in R: A step-by-step tutorial. The Quantitative Methods for Psychology, 12(3):154-174, 2016.

[61] M Harrer, P Cuijpers, TA Furukawa, and DD Ebert. Doing meta-analysis with R: A hands-on guide. 2019.

[62] R Bender, T Friede, A Koch, O Kuss, P Schlattmann, G Schwarzer, and G Skipka. Methods for evidence synthesis in the case of very few studies. Research Synthesis Methods, 9(3):382-392, 2018.

[63] MA Rodgers and JE Pustejovsky. Evaluating meta-analytic methods to detect selective reporting in the presence of dependent effect sizes. Psychological Methods, 26(2):141, 2021.

[64] Shinichi Nakagawa, Malgorzata Lagisz, Michael D Jennions, Julia Koricheva, Daniel WA Noble, TH Parker, A Sánchez-Tójar, Y Yang, and RE O’Dea. Methods for testing publication bias in ecological and evolutionary meta-analyses. Methods in Ecology and Evolution, 2021.

[65] PA García-Parisi and M Omacini. Arbuscular mycorrhizal fungi can shift plant-soil feedback of grass-endophyte symbiosis from negative to positive. Plant and Soil, 419(1):13-23, 2017.

[66] TL Springer. Allelopathic effects on germination and seedling growth of clovers by endophytefree and-infected tall fescue. Crop Science, 36(6):1639-1642, 1996.

[67] M Omacini, EJ Chaneton, L Bush, and CM Ghersa. A fungal endosymbiont affects host plant recruitment through seed-and litter-mediated mechanisms. Functional Ecology, 23(6):1148$1156,2009$.

[68] FM Padilla, WB Mattingly, BL Swedo, K Clay, and HL Reynolds. Negative plant-soil feedbacks dominate seedling competitive interactions of North American successional grassland species. Journal of Vegetation Science, 23(4):667-676, 2012.

[69] PA García-Parisi, FA Lattanzi, AA Grimoldi, M Druille, and M Omacini. Three symbionts involved in interspecific plant-soil feedback: epichloid endophytes and mycorrhizal fungi affect the performance of rhizobia-legume symbiosis. Plant and Soil, 412(1-2):151-162, 2017. 
[70] K Saikkonen, K Ruokolainen, O Huitu, PE Gundel, T Piltti, CE Hamilton, and M Helander. Fungal endophytes help prevent weed invasions. Agriculture, Ecosystems $\&$ Environment, 165:1-5, 2013.

[71] SL McKenzie. The effect of Neotyphodium grass endophyte on alkaloid profiles, dry matter production and botanical composition of perennial ryegrass pastures. $\mathrm{PhD}$ thesis, Lincoln University, 2014.

[72] JPT Higgins, J Thomas, J Chandler, M Cumpston, T Li, MJ Page, and VA Welch. Cochrane Handbook for Systematic Reviews of Interventions. John Wiley \& Sons, 2019.

[73] M Libault, L Brechenmacher, J Cheng, D Xu, and G Stacey. Root hair systems biology. Trends in Plant Science, 15(11):641-650, 2010.

[74] DW Lucero, P Grieu, and A Guckert. Water deficit and plant competition effects on growth and water-use efficiency of white clover (Trifolium repens, L.) and ryegrass (Lolium perenne, L.). Plant and Soil, 227(1):1-15, 2000.

[75] R Ball, LF Molloy, and DJ Ross. Influence of fertiliser nitrogen on herbage dry matter and nitrogen yields, and botanical composition of a grazed grass-clover pasture. New Zealand Journal of Agricultural Research, 21(1):47-55, 1978.

[76] T Andy Williams, DR Evans, I Rhodes, and MT Abberton. Long-term performance of white clover varieties grown with perennial ryegrass under rotational grazing by sheep with different nitrogen applications. The Journal of Agricultural Science, 140(2):151-159, 2003.

[77] DR Evans and TA Williams. The effect of cutting and grazing managements on dry matter yield of white clover varieties (Trifolium repens) when grown with S23 perennial ryegrass. Grass and Forage Science, 42(2):153-159, 1987.

[78] JL Brock and MJM Hay. A review of the role of grazing management on the growth and performance of white clover cultivars in lowland New Zealand pastures. New Zealand Grassland Association: Research and Practice Series, 6:65-70, 1995.

[79] M Omacini, EJ Chaneton, and CM Ghersa. A hierarchical framework for understanding the ecosystem consequences of endophyte-grass symbioses. In CA Roberts, CP West, and DE Spiers, editors, Neotyphodium in Cool-Season Grasses, pages 141-157. Blackwell, Ames, Iowa, USA, 2005.

[80] D Malinowski, A Leuchtmann, D Schmidt, and J Nösberger. Symbiosis with Neotyphodium uncinatum endophyte may increase the competitive ability of meadow fescue. Agronomy Journal, 89(5):833-839, 1997.

[81] K Clay, S Marks, and GP Cheplick. Effects of insect herbivory and fungal endophyte infection on competitive interactions among grasses. Ecology, 74(6):1767-1777, 1993. 
[82] M Omacini, EJ Chaneton, CM Ghersa, and P Otero. Do foliar endophytes affect grass litter decomposition? a microcosm approach using Lolium multiflorum. Oikos, 104(3):581-590, 2004.

[83] A Lemons, K Clay, and JA Rudgers. Connecting plant-microbial interactions above and belowground: a fungal endophyte affects decomposition. Oecologia, 145(4):595-604, 2005.

[84] M Omacini, M Semmartin, LI Pérez, and PE Gundel. Grass-endophyte symbiosis: a neglected aboveground interaction with multiple belowground consequences. Applied Soil Ecology, 61:273-279, 2012.

[85] M Chu-Chou, B Guo, Z-Q An, JW Hendrix, RS Ferriss, MR Siegel, CT Dougherty, and PB Burrus. Suppression of mycorrhizal fungi in fescue by the Acremonium coenophialum endophyte. Soil Biology and Biochemistry, 24(7):633-637, 1992.

[86] KML Mack and JA Rudgers. Balancing multiple mutualists: asymmetric interactions among plants, arbuscular mycorrhizal fungi, and fungal endophytes. Oikos, 117(2):310-320, 2008.

[87] MV Novas, LJ Iannone, AM Godeas, and D Cabral. Positive association between mycorrhiza and foliar endophytes in Poa bonariensis, a native grass. Mycological Progress, 8(1):75, 2009.

[88] MV Novas, LJ Iannone, AM Godeas, and JM Scervino. Evidence for leaf endophyte regulation of root symbionts: effect of Neotyphodium endophytes on the pre-infective state of mycorrhizal fungi. Symbiosis, 55(1):19-28, 2011.

[89] LC Slaughter and RL McCulley. Aboveground Epichloë coenophiala-grass associations do not affect belowground fungal symbionts or associated plant, soil parameters. Microbial Ecology, 72(3):682-691, 2016.

[90] LC Slaughter, AE Carlisle, JA Nelson, and RL McCulley. Fungal endophyte symbiosis alters nitrogen source of tall fescue host, but not nitrogen fixation in co-occurring red clover. Plant and Soil, 405(1-2):243-256, 2016.

[91] JW Matthews and K Clay. Influence of fungal endophyte infection on plant-soil feedback and community interactions. Ecology, 82(2):500-509, 2001.

[92] X Rojas, J Guo, JW Leff, DH McNear, Noah F, and RL McCulley. Infection with a shootspecific fungal endophyte (Epichloë) alters tall fescue soil microbial communities. Microbial Ecology, 72(1):197-206, 2016.

[93] BK Ehlers. Soil microorganisms alleviate the allelochemical effects of a thyme monoterpene on the performance of an associated grass species. PloS One, 6(11):e26321, 2011.

[94] J Guo, RL McCulley, TD Phillips, and DH McNear Jr. Fungal endophyte and tall fescue cultivar interact to differentially affect bulk and rhizosphere soil processes governing $\mathrm{C}$ and $\mathrm{N}$ cycling. Soil Biology and Biochemistry, 101:165-174, 2016. 
[95] RS Zeng. Allelopathy-the solution is indirect. Journal of Chemical Ecology, 40(6):515-516, 2014.

[96] S Nakagawa and ESA Santos. Methodological issues and advances in biological meta-analysis. Evolutionary Ecology, 26(5):1253-1274, 2012.

[97] A Leuchtmann, CW Bacon, CL Schardl, JF White Jr, and M Tadych. Nomenclatural realignment of neotyphodium species with genus Epichloë. Mycologia, 106(2):202-215, 2014.

[98] JA Newman, S Gillis, and HA Hager. Costs, benefits, parasites and mutualists: The use and abuse of the mutualism-parasitism continuum concept for Epichloë fungi. Philosophy, Theory and Practice in Biology, 2021.

[99] A Hodge and AH Fitter. Microbial mediation of plant competition and community structure. Functional Ecology, 27(4):865-875, 2013. 